\title{
Validation of dental X-ray by cytokine RANTES - comparison of $X$-ray findings with cytokine overexpression in jawbone
}

This article was published in the following Dove Press journal:

Clinical, Cosmetic and Investigational Dentistry

2I August 2014

Number of times this article has been viewed

\section{Johann Lechner}

Clinic for Integrative Dentistry, Munich, Germany
Correspondence: Johann Lechner Clinic for Complementary Dentistry, IOA Gruenwalder St, 81547 Munich, Germany

Tel +49896970055

Fax +49896925830

Email drlechner@aol.com
Introduction: There is a need to clarify the extent to which the most common diagnostic tool in dentistry - two-dimensional panoramic tomography (2D-OPG) - is suitable for identifying fatty degenerative osteolysis of jawbone (FDOJ).

Materials and methods: To obtain a qualitative assessment of edentulous jawbone sections, the results from 2D-OPG with a defined X-ray density $(\mathrm{XrDn})$, expression of the cytokine RANTES (regulated on activation, normal T-cell expressed and secreted), and a transalveolar ultrasound system for measuring jawbone density were compared.

Results: The difference in the XrDn of healthy jawbone and FDOJ are minimal, whereas RANTES is up to 25-fold higher in FDOJ. In contrast to 2D-OPG, transalveolar ultrasound showed coincidental findings in FDOJ areas.

Discussion: Comparisons of the data revealed a discrepancy between the XrDn of 2D-OPGs and the medullary osteopathies in the jawbone like FDOJ.

Conclusion: The data suggest that there is a critical attitude toward the use of 2D-OPG as a sole imaging diagnostic tool for assessing chronic inflammatory processes in the jawbone. Specifically, 2D-OPG is objectively not suitable for depicting FDOJ.

Keywords: osteonecrotic jawbone, silent inflammation, RANTES, bone density measurement

\section{Introduction}

All X-ray findings of the jawbone are obtained by means of an optical and visual assessment by the observer. The risk of subjective distortion of the assessment is large, and it generally diminishes with the establishment of reliable criteria of a scientifically objectified procedure. Fatty degenerative osteolytic or chronically osteonecrotic changes of jawbone (FDOJ) seem to present particular problems in dental X-ray diagnostics, which is why they often go undetected in terms of etiology and pathogenesis. ${ }^{1}$ Undetected FDOJ might also be a problem for the long-term stability of dental implants. ${ }^{2}$ By comparing X-ray findings with the corresponding expression of proinflammatory mediator regulated on activation, normal T-cell expressed and secreted (RANTES)/C-C motif ligand 5 (CCL5) in the same area of jawbone, this study tries to elucidate whether important silent inflammation in the jawbone remains undetected.

\section{Limitations of X-ray diagnostics in dentistry}

The limitations of two-dimensional panoramic tomography (2D-OPG) have been sufficiently proven scientifically: apical changes cannot be reliably assessed in 2D-OPG; and $34 \%$ of these changes are not detected. One-third to one-half of all 2D-OPG images are therefore not sufficiently informative for dental diagnostics. ${ }^{3} \ln$ dentistry, 
the structure of the jawbone is often assessed by 2D-OPG with reliable results if there is cortical damage. However, significant limitations in the assessment of medullary bone must be taken into account. ${ }^{3-5}$

\section{Imaging FDOJ with X-ray}

A typical case of FDOJ shows little formation of new bone and little sign of healing. In the area affected by FDOJ, there are medullary cavities. The cortical bone is generally intact, and during operation, a clear demarcation can be observed between the cortical bone not involved and the medullary bone eroded by the cavities. FDOJ often presents as fatty clumps of tissue. ${ }^{6}$ Figure 1 shows one such tissue sample where the majority of the cancellous bone has been converted into fat. FDOJ is characterized by the absence of typical signs of inflammation and by typical fatty erosion and cavities in the medullary jawbone. ${ }^{6}$ FDOJ must not be confused with classic osteomyelitis. For FDOJ, the etiology is still largely unknown. ${ }^{7}$ Radiographic symptoms can be so subtle that they are almost impossible to identify without extensive diagnostic experience. ${ }^{8}$ The problem of X-ray imaging contributes to the neglect of FDOJ as a pathological and pathogenetic change in the jawbone. Other authors also pointed out a significant discrepancy between X-ray findings and the structural abnormality of FDOJ. ${ }^{9}$ To elucidate this problem, this study examines the reliability of 2D-OPG and attempts to shed light on this with the following questions: is dental 2D-OPG a reliable parameter for identifying medullar changes in the context of FDOJ? Or is it possible that changes in the metabolism

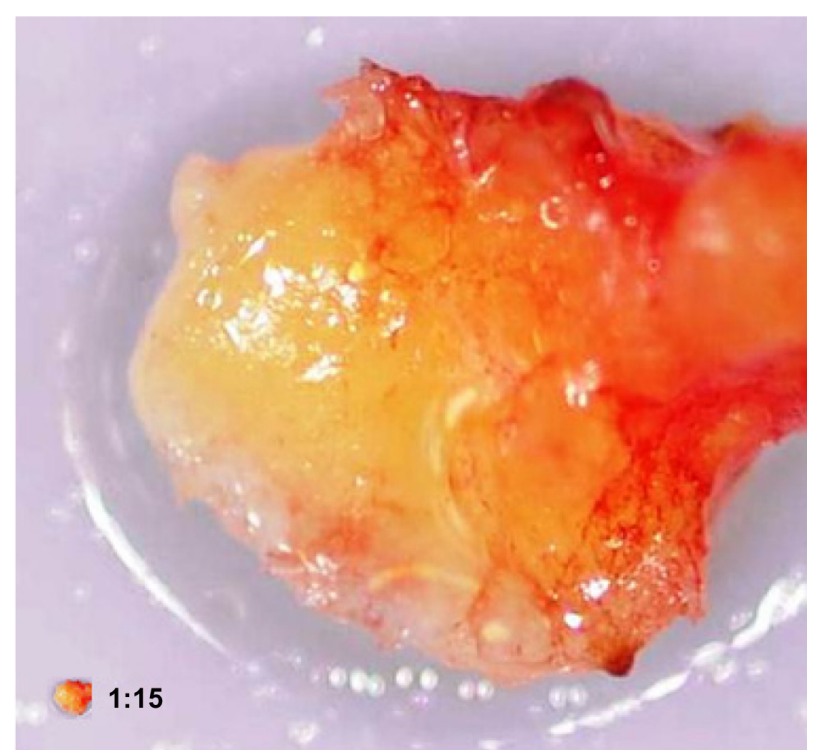

Figure I Fatty degenerative osteolysis/osteonecrosis with typical fatty degenerative changes. of the jawbone may go undetected by 2D-OPG? Is FDOJ eventually connected with systemic diseases?

\section{Material and methods}

This study was performed as a randomized controlled trial. As we showed in an earlier publication, ${ }^{6}$ the defining feature of areas of FDOJ include overexpression of the proinflammatory messenger RANTES, which is in contrast to what is seen in normal jawbone. In this study, we will compare areas of FDOJ defined by high levels of RANTES with the corresponding X-ray density (XrDn) in 2D-OPG. In addition, $\mathrm{XrDn}$ is compared with transalveolar ultrasound (TAU) images. Research is based on data retrieved from patients during normal dental surgery. All patients gave their written informed consent.

\section{Groups of patients examined}

The cases examined consisted of two groups. FDOJ was found in 31 patients. The age range of this group of patients extended from $27-87$ years, with an average age of 57 years and a sex ratio (female/male) of 21/10. The age range of the control group that consisted of 19 patients without findings of FDOJ extended from 38-71 years, with an average age of 54 years and a sex ratio (female/male) of $11 / 8$. The research is based on data retrieved from patients during normal dental surgery. All patients gave their written informed consent. Samples of healthy jawbone were taken from drill cores during normal dental implantation surgery. Inclusion criteria for this group were: no radiologically distinctive features on 2D-OPG; and inconspicuous TAU measurements of bone density in the implantation range. Bisphosphonate medication was the central exclusion criteria for both groups. The mandatory inclusion criterion for all test subjects was the availability of a 2D-OPG image, produced with our own X-ray machine, in order to allow for reliable comparisons. The existence of a 2D-OPG image produced by a third party was an exclusion criterion. A further inclusion criterion for the group who underwent surgery for FDOJ was a measurement of the jawbone density by TAU. The use of bisphosphonates and a clinical diagnosis of osteoporosis were exclusion criteria.

\section{Reliability of information on X-ray density of the $\mathrm{X}$-ray machine used}

To obtain objectively based data when assessing 2D-OPGs, we used the XrDn achieved by the Kodak 9000 Extraoral Imaging System X-ray machine in combination with the Kodak Dental Imaging software version 6.12.11.0 
(Eastman Kodak, Rochester, NY, USA) as a numerical variable in definable areas of the jaw. Our paper only compares $\mathrm{XrDn}$ values in 2D-OPG images obtained from this machine taken in the author's practice between 2010 and 2013. To verify the reliability and plausibility of this function, we carried out measurements on six randomly selected 2D-OPG reference values; XrDn was measured at four different points in the 2D-OPG, with a calibrated $1 \mathrm{~cm}$ rule length, thereby creating a guiding measurement scale of different XrDns. Values of measurement are shown without specific units (see the Reference values for validating X-ray density section).

\section{Preparation of necrotic tissue samples}

Samples of FDOJ with a volume of up to $0.5 \mathrm{~cm}^{3}$ were spooned out and immediately added to a dry, sterile receptacle (Sarstedt microtube; Sarstedt AG and Co, Nümbrecht, Germany) and stored in a freezer at $-20^{\circ} \mathrm{C}$. At the examining Institute for Medical Diagnostics (Berlin, Germany), as inspected by Deutsche Akkreditierungsstelle $\mathrm{GmbH}$ (DAkks, Berlin, Germany; accredited to DIN EN ISO/IEC 17025:2005 and DIN EN ISO 15189:2007), FDOJ samples were homogenized in $200 \mu \mathrm{L}$ of protease buffer (cOmplete Mini Protease Inhibitor Cocktail; Hoffman-La Roche Ltd, Basel, Switzerland). The homogenate was centrifuged for 15 minutes at $13,400 \mathrm{rpm}$. The supernatant was then removed and centrifuged at $13,400 \mathrm{rpm}$ for a further 25 minutes. RANTES was measured in the supernatant of the tissue homogenate with the human cytokine/chemokine panel I (EMD Millipore, Billerica, MA, USA) and with the Luminex ${ }^{\circledR} 200^{\mathrm{TM}}$ analyzer and xPONENT ${ }^{\circledR}$ software (Luminex Corporation, Austin, TX, USA).

\section{Ultrasound measurement of bone density - TAU measurement}

TAU is a useful tool to establish FDOJ. TAU devices measure reductions in the sound velocity when the "FDOJ bubble" has been penetrated. ${ }^{10,11}$ Ultrasound is completely reflected by the cortical bone; therefore, TAU uses a frequency range of 2.5-2.75 MHz, which penetrates the cortical bone. An ultrasound transmitter is placed over the jaw area and a thumbnail-sized receiver is placed inside the mouth. The transmitter and receiver sit opposite each other, with the receiver containing 64 piezoelectric fields for registering the sound waves, which are converted into a colored graph of the bone density (Figure 2): green for healthy and solid bone; yellow for ischemic metabolism; and orange and red for FDOJ areas.

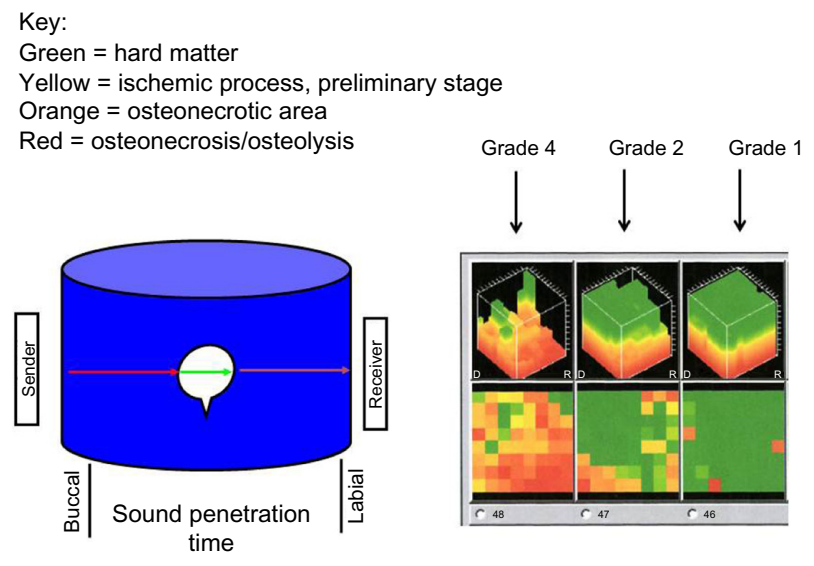

Figure 2 Principle of transalveolar ultrasound measurement of bone density. Note: Explanation of grading: green $=$ hard matter, Grade I; yellow = ischemic process, preliminary stage, Grade 2; orange = osteonecrotic area, Grade 3; Red = osteonecrosis/osteolysis, Grade 4.

\section{Results \\ Reference values for validating X-ray density}

Four areas with defined different densities in the 2D-OPG (that do not correspond to the Hounsfield units in computed tomography) provide a guiding scale: 1) six metal crowns evince an average of $245 ; 2$ ) six measurements directly on the oblique line of the mandibular ramus show an average of 161 ; 3) six measurements directly in the nerve canal of the lower jaw produced an average of 127 ; and 4) six measurements in the toothless area of area 38/48 and the retromolar areas of the ascending mandibular ramus - referred to in short as "region 39" and "region 49" here - revealed an average of 134. Figure 3 shows the method used and the display in the X-ray machine. These reference values can be plausibly compared and are used by us further in this study.

\section{Immune messengers and X-ray density of healthy jawbone}

Nineteen samples of healthy jawbone were taken from drilled implants in normal jawbone and - as described in the Preparation of necrotic tissue samples section - they were also examined for seven immune mediators. XrDn of the same area in 2D-OPG before implantation was measured. Figure 4 shows the mean fibroblast growth factor- 2 at 27.6 $\mathrm{pg} / \mathrm{mL}($ median $=9.52 \mathrm{pg} / \mathrm{mL}$; standard deviation [SD] $=36.02 \mathrm{pg} / \mathrm{mL}$ ), interleukin (IL)-1 receptor antagonist at $196.5 \mathrm{pg} / \mathrm{mL}$ (median $=9.29 \mathrm{pg} / \mathrm{mL} ; \mathrm{SD}=569.3 \mathrm{pg} / \mathrm{mL})$, IL-6 at $101.0 \mathrm{pg} / \mathrm{mL}$ (median $=26.0 \mathrm{pg} / \mathrm{mL} ; \mathrm{SD}=81.69 \mathrm{pg} / \mathrm{mL}), \mathrm{IL}-8$ at $7.5 \mathrm{pg} / \mathrm{mL}$ (median $=4.5 \mathrm{pg} / \mathrm{mL} ; \mathrm{SD}=3.9 \mathrm{pg} / \mathrm{mL}$ ), monocyte chemoattractant protein- 1 at $20.3 \mathrm{pg} / \mathrm{mL}$ (median $=18.6 \mathrm{pg} / \mathrm{mL}$; $\mathrm{SD}=20.5 \mathrm{pg} / \mathrm{mL}$ ), tumor necrosis factor- $\alpha$ at $11.5 \mathrm{pg} / \mathrm{mL}$ 


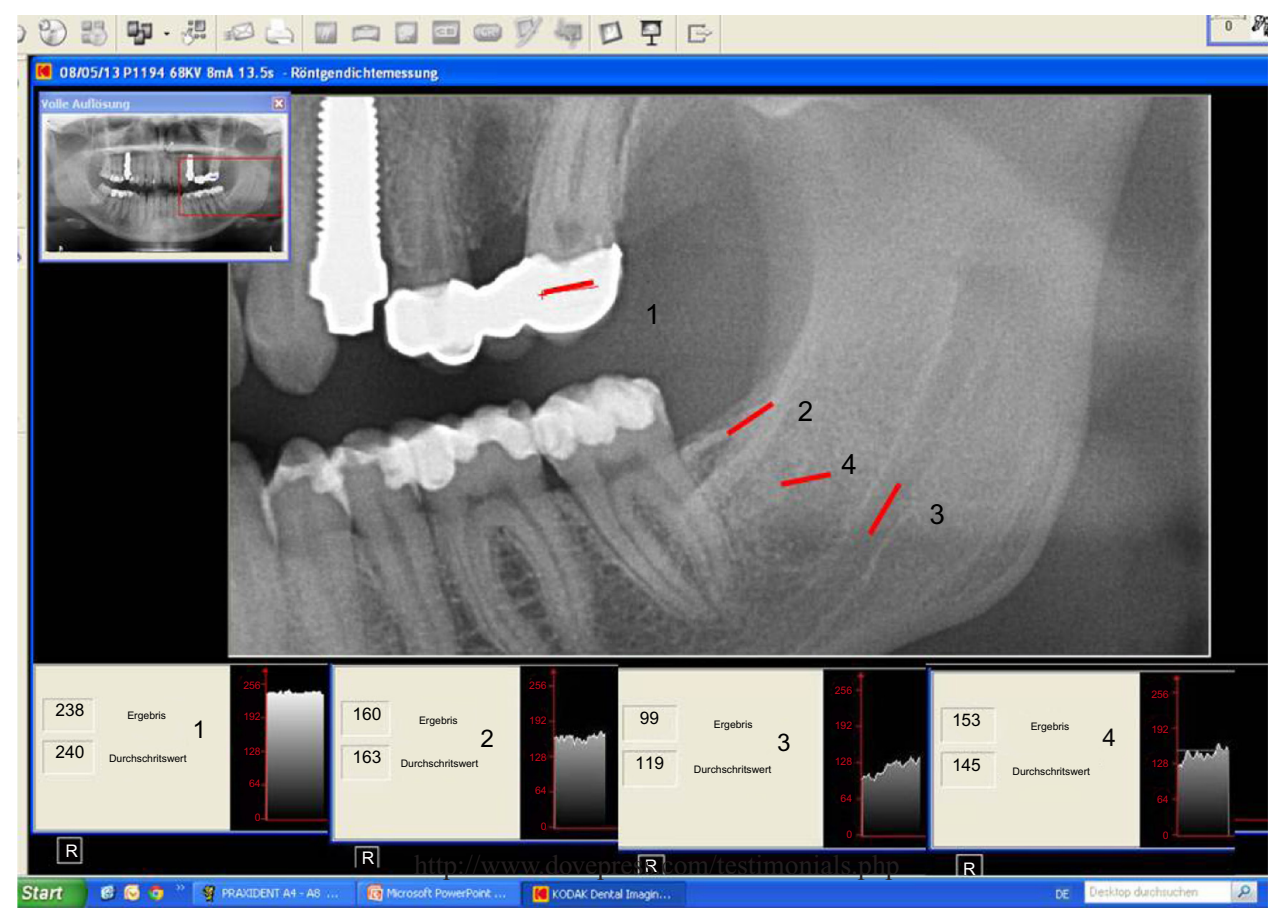

Figure 3 Procedure for measuring $X$-ray density in four defined areas.

Note: Numbers in each box describe X-ray density without units according to Kodak Dental Imaging software version 6.I2.II.0 (Eastman Kodak, Rochester, NY, USA).

( median $=11.45 \mathrm{pg} / \mathrm{mL} ; \mathrm{SD}=3.19 \mathrm{pg} / \mathrm{mL}$ ), and RANTES at $149.9 \mathrm{pg} / \mathrm{mL}$ (median $=119.9 \mathrm{pg} / \mathrm{mL} ; \mathrm{SD}=130.5 \mathrm{pg} / \mathrm{mL}$ ). The mean of the corresponding $\mathrm{XrDn}$ in 19 healthy jawbone areas is $125 \mathrm{pg} / \mathrm{mL}$ ( $\operatorname{median}=125.08 \mathrm{pg} / \mathrm{mL} ; \mathrm{SD}=23.35 \mathrm{pg} / \mathrm{mL}$ ). Values $<3.2$ were recorded as 3.2. There was a correlation between fibroblast growth factor-2 and RANTES in neuralgia-inducing cavitational osteonecrosis tissue $(P<0.01$; Spearman's rho coefficient 0.607 ), but not between the other mediators.

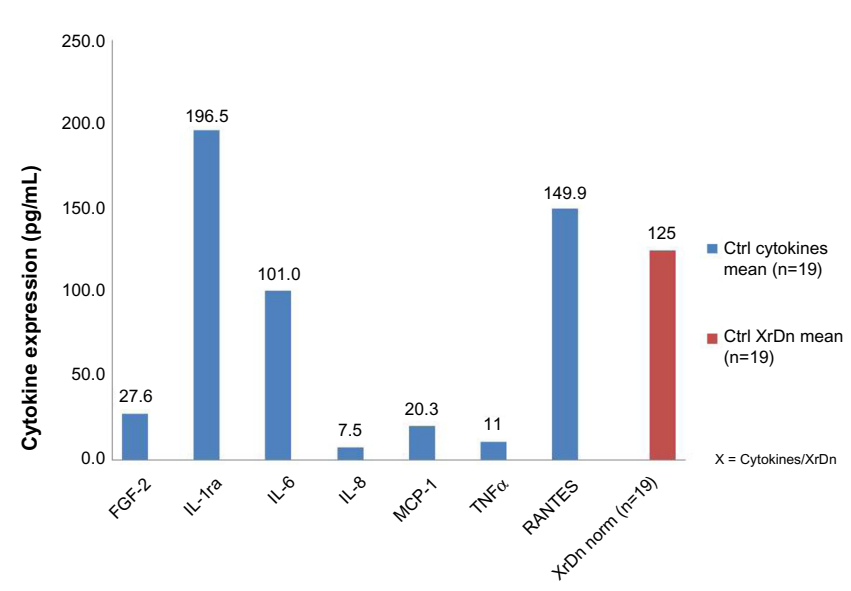

Figure 4 Distribution of seven cytokines and X-ray density in healthy controls $(n=19)$ Abbreviations: FGF-2, fibroblast growth factor 2; IL-I ra, interleukin I receptor antagonist; IL, interleukin; MCP-I, monocyte chemoattractant protein I; TNF $\alpha$, tumor necrosis factor alpha; RANTES, regulated upon activation, normal T-cell expressed and secreted chemokine (C-C motif) ligand 5; XrDn norm, $\mathrm{X}$-ray density in the group of healthy jawbone; n, number; Ctrl cytokines, cytokine expression in the control group; Ctrl XrDn mean, mean values of the X-ray density in healthy jawbone.

\section{Hyperactivated chemokine RANTES in FDOJ}

In previous studies, ${ }^{6}$ we found a 21 -fold overexpression of chemokine RANTES in 31 samples of FDOJ compared to normal jawbone (Figure 5). Since we are exploring the suitability of 2D-OPG for diagnosing FDOJ, Figure 5 also shows the mean preoperative $\mathrm{XrDn}$ in these $31 \mathrm{FDOJ}$ areas; $130.1 \mathrm{pg} / \mathrm{mL}$ (median $=137.6 \mathrm{pg} / \mathrm{mL} ; \mathrm{SD}=21.64 \mathrm{pg} / \mathrm{mL}$ ).

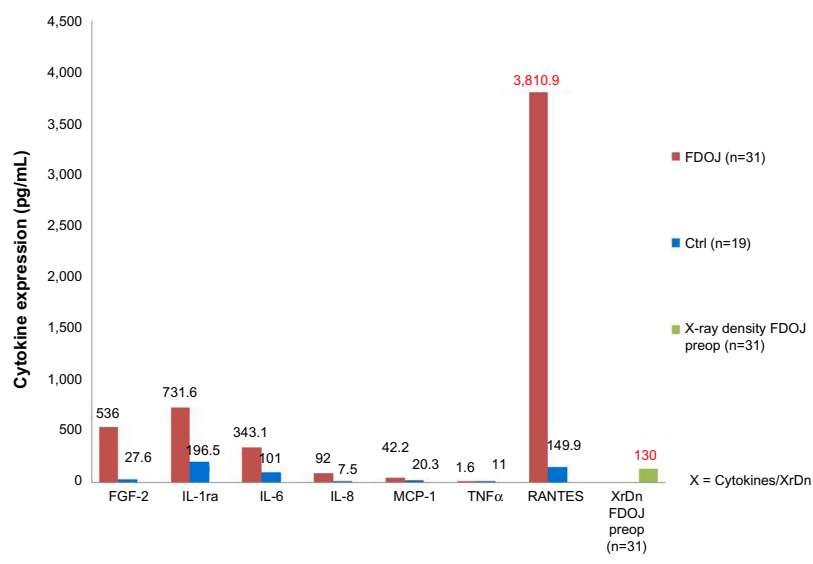

Figure 5 Distribution of seven cytokines in 31 FDOJ samples and 19 healthy controls. Note: The right green column is the mean $\mathrm{XrDn}$ in FDOJ cases $(n=31)$.

Abbreviations: FGF-2, fibroblast growth factor 2; IL-I ra, interleukin I receptor antagonist; IL, interleukin; MCP-I, monocyte chemoattractant protein I; TNF $\alpha$, tumor necrosis factor alpha; RANTES, regulated upon activation, normal T-cell expressed and secreted chemokine ( $\mathrm{C}-\mathrm{C}$ motif) ligand 5; $\mathrm{XrDn}$ FDOJ preop, $\mathrm{X}$-ray density in areas of fatty degenerative osteonecrosis of jawbone before operation; $n$, number; FDOJ, fatty degenerative osteolysis of jawbone; Ctrl, control; XrDn, X-ray density. 
RANTES/CCL-5 is a proinflammatory chemokine. The significance of RANTES for the development of diseases seems to be enormous - RANTES interferes with immune responses on a number of levels and therefore plays a crucial role in pathological states. ${ }^{12}$ The chemotactic properties of RANTES send T-cells, dendritic cells, eosinophils, natural killer cells, mast cells, and basophils to the sites of inflammation and infection. ${ }^{13}$ RANTES is also an effective activator of leukocytes, which play a key role in a wide range of inflammatory disorders ${ }^{14}$ (ie, in rheumatoid arthritis, ${ }^{15}$ and in diseases of the central nervous system such as multiple sclerosis $\left.{ }^{16}\right)$. In Morbus Hodgkin, malignant Reed-Sternberg cells (Hodgkin Reed-Sternberg cells) produce RANTES, which provokes the chemotactic migration of mast cells into the tumor tissue. Hodgkin lymphoma cell lines mainly express RANTES in vivo. ${ }^{17}$ RANTES has also been associated with the induction or promotion of cancer. ${ }^{18}$ The development of breast cancer is the potential ability of RANTES to act directly on the tumor cells, and to promote progression of the tumor. ${ }^{19}$ RANTES levels were markedly elevated in the primary tumor and in metastatic lesions from all patients with breast and cervical cancer. This study suggests an as-yet-undefined but important role played by RANTES in carcinogenesis. ${ }^{20}$

\section{Measurement of jawbone density with TAU}

TAU was developed to measure bone density objectively in the areas of FDOJ. ${ }^{21,22}$ For objective grading, we divided TAU into four stages of FDOJ, ranging from grade 1, with a majority of green/healthy bone, to grade 4, with orange/ osteonecrotic parts and red/cavities and hollow areas. It should be noted that the higher the grade, the lower the bone density, and the greater the suspicion of FDOJ. Figure 6 shows a mean preoperative TAU of 1.2 for 19 healthy controls and the corresponding RANTES expression, and the mean TAU of 3.5 for 31 FDOJ areas and the corresponding RANTES expression in $\mathrm{pg} / \mathrm{mL}$.

\section{Discussion}

\section{Comparison of XrDn and RANTES expression in healthy jawbone and FDOJ}

The reference XrDn gained in the Reference values for X-ray density section seem plausible and reliable. In Figure 4, we compared XrDn, TAU, and RANTES expression in FDOJ and healthy controls, and we defined $\mathrm{XrDn}$ in healthy jawbone as $125 \mathrm{pg} / \mathrm{mL}$ (number $[\mathrm{n}]=19$ ). Figure 7 compares RANTES expression in 31 FDOJ samples and healthy controls with the

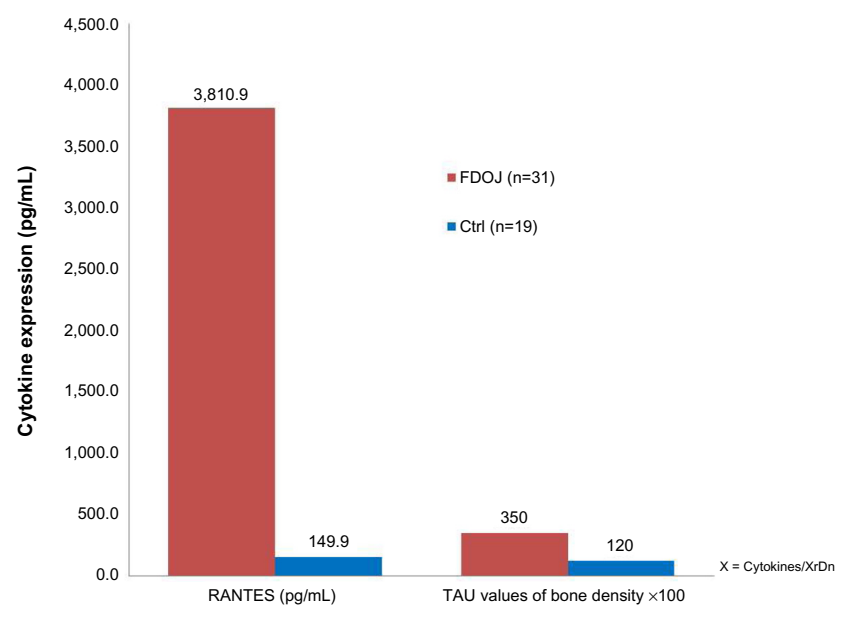

Figure 6 Comparison of RANTES expression and TAU in FDOJ $(n=31)$ and healthy controls $(n=19)$.

Abbreviations: RANTES, regulated upon activation, normal T-cell expressed and secreted chemokine (C-C motif) ligand 5; TAU, transalveolar ultrasonography; FDOJ, fatty degenerative osteonecrosis of jawbone; $n$, number; Ctrl, control.

$\mathrm{XrDn}$ from the reference jawbone $(\mathrm{n}=6$; see the Reference values for X-ray density section), XrDn in healthy controls $(n=19)$, and XrDn in FDOJ samples $(n=31)$. RANTES expression in FDOJ is 25-fold higher than in controls, although this is not evident in $\mathrm{XrDn}$; the FDOJ cohort showed 130, the controls showed 125, and the reference showed 134 in terms of $\mathrm{XrDn}$. The mean $\mathrm{XrDn}$ in control is even lower than that in the FDOJ cohort. In contrast, significantly hyperactivated RANTES in FDOJ in Figure 7 is not reflected in the 2D-OPG X-rays.

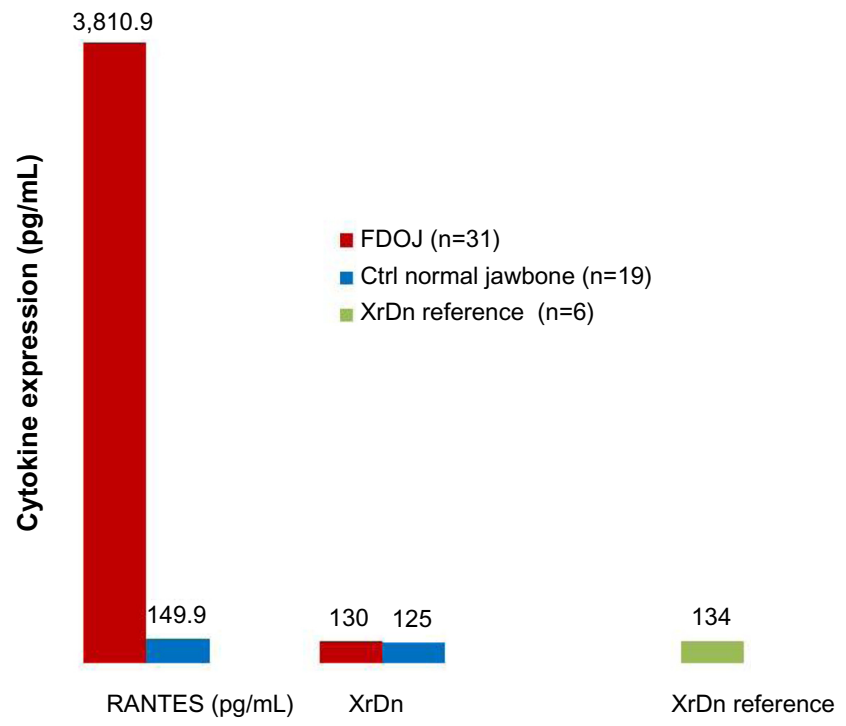

Figure 7 Distribution of RANTES in 3I FDOJ cases and 19 samples of normal jawbone in comparison to $\mathrm{XrDn}$ for both groups in the corresponding areas. Abbreviations: RANTES, regulated upon activation, normal T-cell expressed and secreted chemokine (C-C motif) ligand 5; XrDn, X-ray density; FDOJ, fatty degenerative osteonecrosis of jawbone; $n$, number; Ctrl, control. 


\section{Comparison of $\mathrm{XrDn}$ and FDOJ using contrast agent}

In order to document the noncoincidental representation of FDOJ in 2D-OPG, as well as to determine the intramedullary extent of FDOJ, we injected a contrast agent into the FDOJ area after curetting the softened cancellous bone (see Figure 8). Upper section of X-ray showed the preoperative 2D-OPG of the same retromolar area, which featured inconspicuous bony structures. Optical analysis of the 2D-OPG diagnosed a "normal/healthy" jawbone. The right columns compared the $\mathrm{XrDn}$ for these FDOJ areas with the $\mathrm{XrDn}$ of normal jawbone $(n=19)$ and the mean XrDn in 31 FDOJ cases. Preoperative $\mathrm{XrDn}$ is higher than the $\mathrm{XrDn}$ for normal jawbone, although there is massive osteolysis in region 48/49. The lower section of X-ray in Figure 8 shows the dimension of the contrast agent filling up the FDOJ postoperatively, which is not adequately recorded by preoperative $2 \mathrm{D}-\mathrm{OPG}$.

\section{Comparison of preoperative and postoperative $\mathrm{XrDn}$ in FDOJ with RANTES expression}

Individual case comparing preoperative and postoperative 2D-OPG with RANTES expression in FDOJ: Figures 9 and 10 compare the preoperative and postoperative $2 \mathrm{D}-\mathrm{OPG}$ in area $38 / 39$, with the corresponding fatty degenerated cancellous bone typical of FDOJ in area 38/39 after removal of the cortical bone, and the corresponding RANTES expression at operation site 38/39 when compared to controls. The noticeable feature of the multiplex analysis is the 50-fold overexpressed RANTES levels in area 38/39 (7,523.1 pg/ $\mathrm{mL}$ ). The absence of any difference between the preoperative and postoperative 2D-OPG in the optical display, as well as between the preoperative (140) and postoperative $\mathrm{XrDn}$ (138) in the right two columns in Figure 10, is impressive.

\section{Comparison of $\mathrm{XrDn}$ in controls with preoperative/postoperative 2D-OPG, with RANTES expression, and with TAU}

In a group of 15 patients with preoperative and postoperative 2D-OPG, we could compare the concurrent RANTES expression from the curetted FDOJ areas. Figure 11 shows the $\mathrm{XrDn}$ before and immediately after curettage and the corresponding RANTES expression in FDOJ. As was expected, the XrDn dropped postoperatively, but only by $8 \%$. In contrast, RANTES was approximately 25 -fold higher (around 2,500\%) than that of normal jawbone. The minor differences in $\mathrm{XrDn}$ between preoperative and postoperative

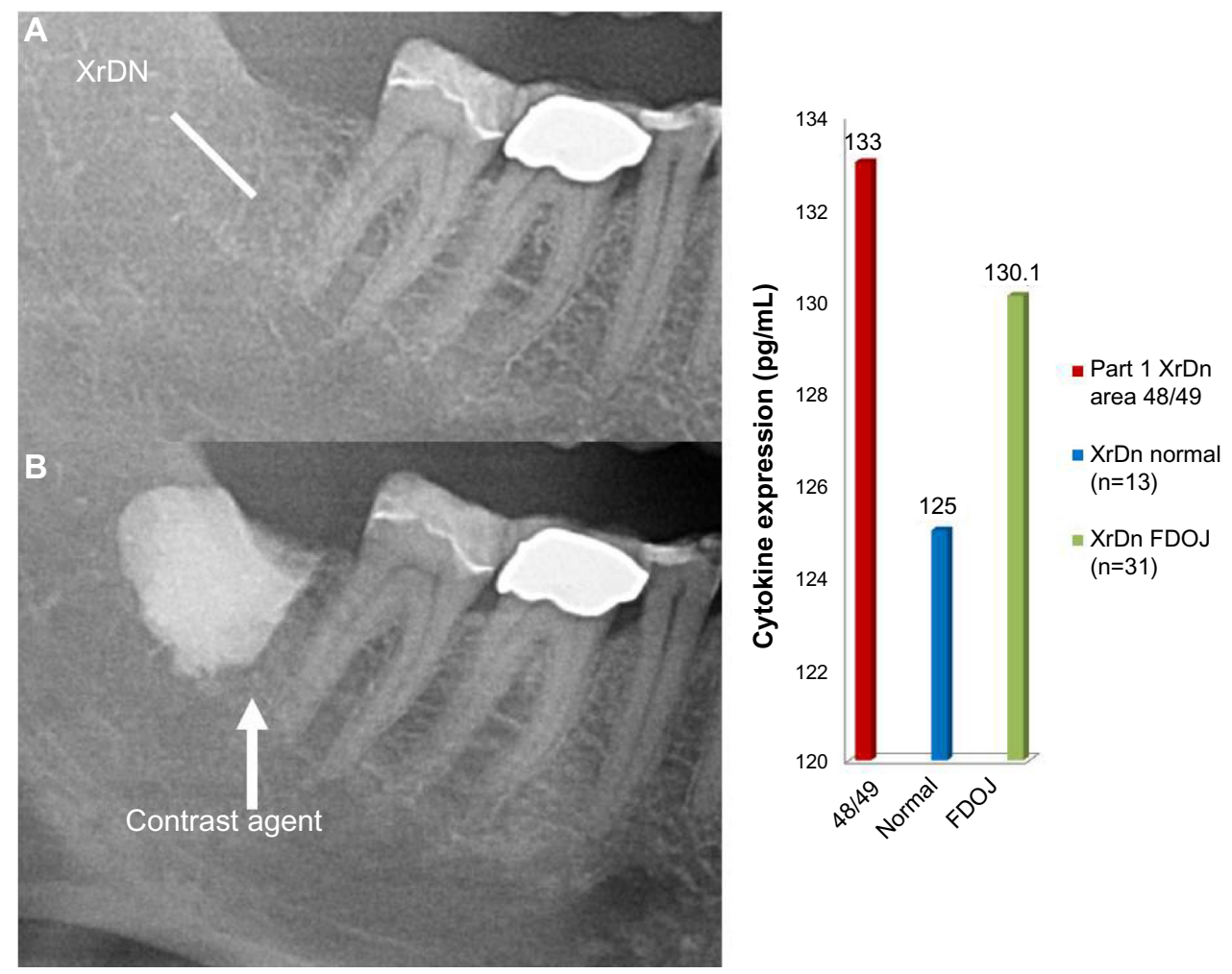

Figure 8 Intraoperative documentation of the extension of FDOJ (B) in the right lower jawbone, area 48/49, by contrast agent (arrow) in contrast to normal $\mathrm{XrDn}(\mathbf{A})$. Notes: Red column is mean preoperative $\mathrm{XrDn}$ in 3 I FDOJ cases; blue column is $\mathrm{XrDn}$ in 15 normal jawbone cases; green column is $\mathrm{XrDn}$ in this specific FDOJ area $48 / 49$ before operation, although contrast medium documents huge FDOJ cavitational extent.

Abbreviations: XrDn, X-ray density; FDOJ, fatty degenerative osteolysis of jawbone; $n$, number. 


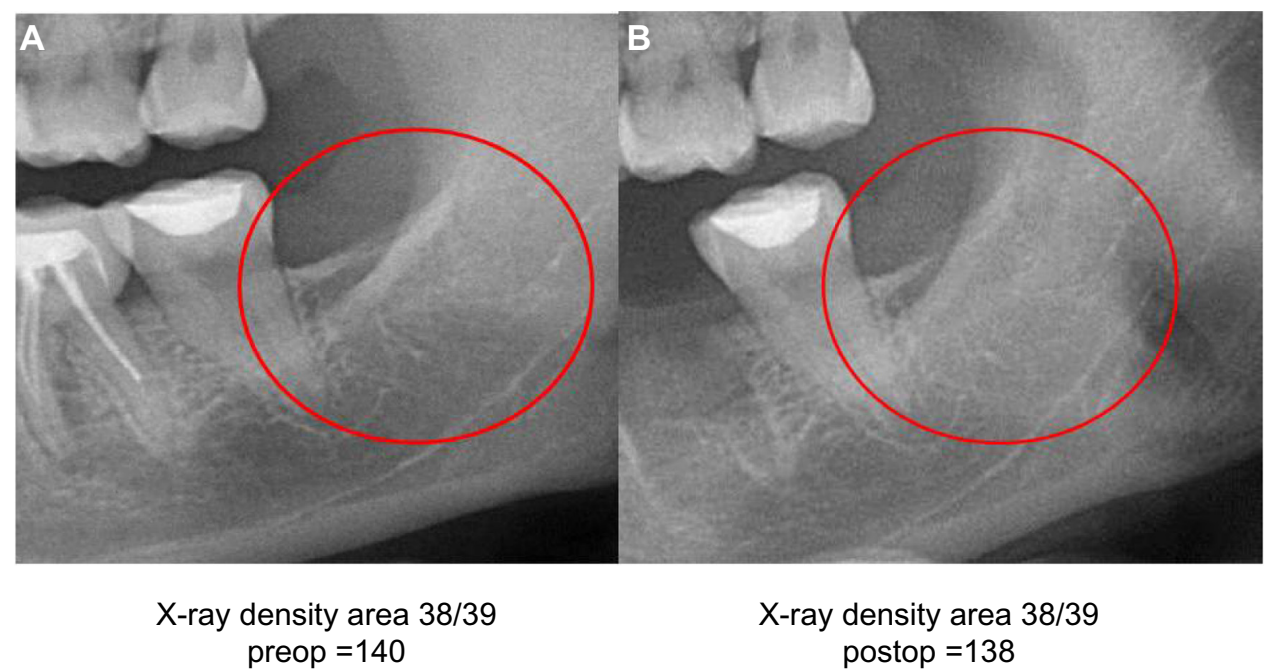

Figure 9 Comparison of 2D-OPG and the average preoperative and postoperative X-ray densities for area 38/39.

Notes: (A) X-ray density area 38/39; preoperative $=140$. (B) $X$-ray density area 38/39; postoperative $=138$. Red circles indicate retromolar areas of $X$-ray diagnosis before and after surgical debridement of FDOJ.

Abbreviation: 2D-OPG, two-dimensional panoramic tomography.

2D-OPGs do not reflect the severely derailed RANTES expression $(3,788 \mathrm{pg} / \mathrm{mL})$. The comparison of healthy control $\mathrm{XrDn}(\mathrm{n}=19)$ at 125 with preoperative $\mathrm{XrDn}$ at 135.5 , with the postoperative $\mathrm{XrDn}(\mathrm{n}=15)$ at 125 and with the concurrently significantly elevated RANTES profile, also demonstrates that FDOJ is not evident when assessing the preoperative $\mathrm{XrDn}$. TAU showed a similar difference in the right columns. The bone density of the mean grade of 3.5 in FDOJ is lower by a factor of three when compared to controls (a mean grade of 1.2). If we apply the same factor (three) to $\mathrm{XrDn}$, the $\mathrm{XrDn}$ in the FDOJ area would have to be reduced to $41(125 / 3=41.6)$. In fact, the postoperative $\mathrm{XrDn}$ in the curetted FDOJ areas was still 125 and had therefore remained unchanged at the level of controls, even though the

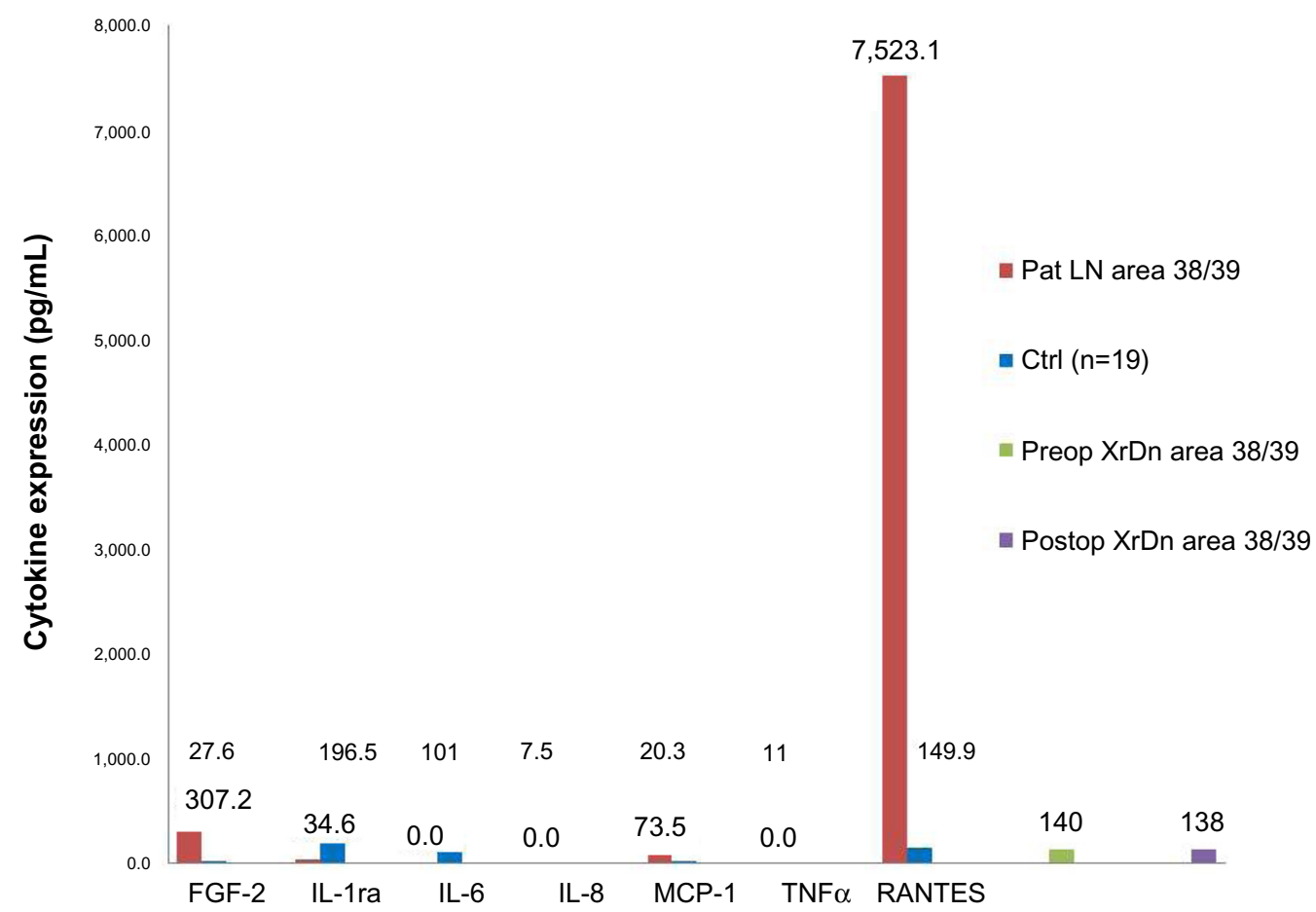

Figure 10 Seven cytokines in FDOJ in region 38/39 in comparison with control and preop and postop XrDn.

Abbreviations: FGF-2, fibroblast growth factor 2; IL-I ra, interleukin I receptor antagonist; IL, interleukin; MCP-I, monocyte chemoattractant protein I; TNF $\alpha$, tumor necrosis factor alpha; RANTES, regulated upon activation, normal T-cell expressed and secreted chemokine (C-C motif) ligand 5; Pat LN, patient LN; Ctrl, control; n, number; preop $\mathrm{XrDn}, \mathrm{X}$-ray density before the operation; postop $\mathrm{XrDn}, \mathrm{X}$-ray density after the operation; FDOJ, fatty degenerative osteolysis of jawbone; $\mathrm{XrDn}$, $\mathrm{X}$-ray density. 


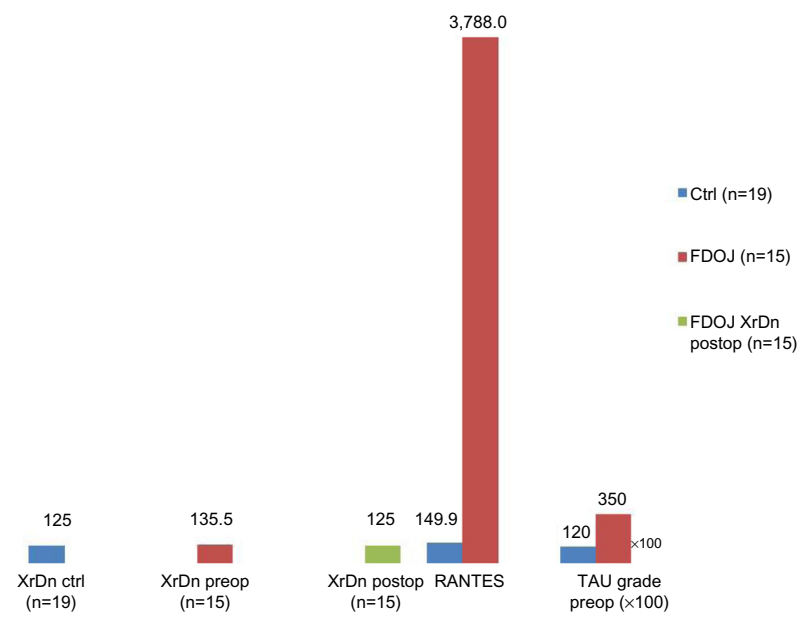

Figure II Comparison of XrDn in healthy Ctrl $(n=19), X r D n$ preop and postop with RANTES $(p g / m L)$ in FDOJ $(n=15)$, and in normal jawbone $(n=19)$.

Abbreviations: $\mathrm{XrDn} \mathrm{Ctrl}$, X-ray density control group; $\mathrm{n}$, number; $\mathrm{XrDn}$ preop, $\mathrm{X}$-ray density before the operation; $\mathrm{XrDn}$ postop, $\mathrm{X}$-ray density after the operation; RANTES, regulated upon activation, normal T-cell expressed and secreted chemokine (C-C motif) ligand 5; TAU grade preop, transalveolar ultrasonography before the operation; Ctrl, control; FDOJ, fatty degenerative osteonecrosis of jawbone; FDOJ XrDn, X-ray density in areas of fatty degenerative osteonecrosis of jawbone; $\mathrm{XrDn}, \mathrm{X}$-ray density.

bony medullary volume had been changed considerably by curetting FDOJ (see the section Comparison of $\mathrm{XrDn}$ and FDOJ using contrasting agent).

\section{Conclusion}

Despite the natural ranges in the data collected, our study demonstrates that $2 \mathrm{D}-\mathrm{OPG}$ is inadequate for reproducing silent inflammation in the jawbone, as well as for reproducing the concomitant cytokine overexpression. This is demonstrated by the strong structural deviations in areas of FDOJ with a contrast agent. When comparing preoperative and postoperative $\mathrm{XrDn}$ in the corresponding areas, we find no noticeable differences from the control group's $\mathrm{XrDn}$ at the FDOJ operation sites, in spite of concurrently high overexpressed proinflammatory RANTES levels. This is proven in a single case where XrDn did not correlate with the derailed RANTES level. The Comparison of preoperative and postoperative XrDn in FDOJ with RANTES expression section confirms this by directly comparing XrDn with positive TAU findings; the corresponding 2D-OPG findings are unsuspicious. Although XrDn in FDOJ - which is significantly marked by hyperactivated RANTES signaling pathways - is identical to that of controls, TAU grades for diminished bone density in FDOJ are more than threefold higher than those of controls. A large number of false-negative findings - based on 2D-OPG - have set the course for the further neglect of FDOJ in dentistry and medicine. Additional examination methods to improve the diagnosis of FDOJ (like TAU) would therefore seem necessary. The 2D-OPG used to identify osteopathies of the jawbone does not show FDOJ areas, with possible negative impacts to systemic health and to the long-life survival of dental implants. To our knowledge, this is the first study to investigate the significance of dental 2D-OPGs in relation to FDOJ with TAU of jawbone density, and with an analysis of inflammatory immune messengers. Further validations of the questions and conclusions presented in this research are required by multicentric studies.

\section{Acknowledgments}

The author would like to thank Professor GE Bouquot for his fundamental research in jawbone cavitations and in ultrasound based diagnosis of this phenomenon. My obligations also belong to $\mathrm{Dr} \mathrm{V}$ von Baehr who provided the cytokine analysis in his laboratory.

\section{Disclosure}

The author reports no conflicts of interest in this work.

\section{References}

1. Patel S, Dawood A, Mannocci F, Wilson R, Pitt Ford T. Detection of periapical bone defects in human jaws using cone beam computed tomography and intraoral radiography. Int Endod J. 2009;42(6):507-515.

2. Al-Nawas B, Klein MO, Götz H, et al. Dental implantation: ultrasound transmission velocity to evaluate critical bone quality - an animal model. Ultraschall Med. 2008;29(3):302-307.

3. Schwartz SF, Foster JK Jr. Roentgenographic interpretation of experimentally produced bony lesions. I. Oral Surg Oral Med Oral Pathol. 1971;32(4):606-612.

4. Ardran GM. Bone destruction not demonstrable by radiography. $\mathrm{Br} \mathrm{J}$ Radiol. 1951;24(278):107-109.

5. Bender IB, Seltzer S. Roentgenographic and direct observation of experimental lesions in bone: I and II. 1961. J Endod. 2003;29(11): $707-712$.

6. Lechner J, von Baehr V. RANTES and fibroblast growth factor 2 in jawbone cavitations: triggers for systemic disease? Int J Gen Med. 2013;6:277-290.

7. Dotti R, Müller DM, Benini A. Clinical appearance, etiology, pathogenesis, diagnosis and treatment of avascular bone necrosis review of present literature. Praxis. 2002;91(5):163-176.

8. Segall RO, del Rio CE. Cavitational bone defect: a diagnostic challenge. J Endod. 1991;17(8):396-400.

9. Bouquot J. In review of NICO (neuralgia-inducing cavitational osteonecrosis), the invisible "osteomyelitis" of the jaws. Presented at Proceedings of Parker Mahan International Conference on Facial Pain; Pantke Institute; April; 1994; Gainesville, Florida.

10. Bouquot JE, Shankland WE II, Margolis M. Through-transmission alveolar ultrasonography (TAU) - new technology for evaluation of bone density and desiccation. Comparison with radiology of 170 biopsied alveolar sites of osteoporotic and ischemic damage [abstract]. Oral Surg Oral Med Oral Pathol Oral Radiol Endod. 2002;93:413-414.

11. Shankland WE, Bouquot JE. Focal osteoporotic marrow defect: report of 100 new cases with ultrasonography scans. Cranio. 2004;22(4): 314-319.

12. Levy JA. The unexpected pleiotropic activities of RANTES. J Immunol. 182(7):3945-3946

13. Appay V, Rowland-Jones SL. RANTES: a versatile and controversial chemokine. Trends Immunol. 2001;22(2):83-87. 
14. von Luettichau I, Nelson PJ, Pattison JM, et al. RANTES chemokine expression in diseased and normal human tissues. Cytokine. 1996;8(1):89-98.

15. Rathanaswami P, Hachicha M, Sadick M, Schall TJ, McColl SR. Expression of the cytokine RANTES in human rheumatoid synovial fibroblasts. Differential regulation of RANTES and interleukin-8 genes by inflammatory cytokines. J Biol Chem. 1993;268(8):5834-5839.

16. Bolin LM, Murray R, Lukacs NW, et al. Primary sensory neurons migrate in response to the chemokine RANTES. J Neuroimmunol. 1998;81(1-2):49-57.

17. Fischer M, Juremalm M, Olsson N, et al. Expression of CCL5/ RANTES by Hodgkin and Reed-Sternberg cells and its possible role in the recruitment of mast cells into lymphomatous tissue. Int J Cancer. 2003;107(2):197-201.

18. Soria G, Ben-Baruch A. The inflammatory chemokines CCL2 and CCL5 in breast cancer. Cancer Lett. 2008;267:271-285.

19. Niwa Y, Akamatsu H, Niwa H, Sumi H, Ozaki Y, Abe A. Correlation of tissue and plasma RANTES levels with disease course in patients with breast or cervical cancer. Clin Cancer Res. 2001;7:285.
20. Azenshtein E, Luboshits G, Shina S, et al. The CC chemokine RANTES in breast carcinoma progression: regulation of expression and potential mechanisms of promalignant activity. Cancer Res. 2002;62(4): 1093-1102.

21. Bouquot J, Martin W, Wrobleski G. Computer-based thru-transmission sonography (CTS) imaging of ischemic osteonecrosis of the jaws a preliminary investigation of 6 cadaver jaws and 15 pain patients [abstract]. Oral Surg Oral Med Oral Pathol Oral Radiol Endod. 2001;92:550.

22. Bouquot JE, Shankland WE II, Margolis M, Glaros W. Throughtransmission alveolar ultrasonography (TAU) - new technology for detection of Iow bone density of the jaws. Comparison with radiology for 92 osteoporotic alveolar sites with histopathologic confirmation. Presented at Proceedings of the annual meeting, American Academy of Oral and Maxillofacial Pathology; April, 2002 New Orleans, LA
Clinical, Cosmetic and Investigational Dentistry

\section{Publish your work in this journal}

Clinical, Cosmetic and Investigational Dentistry is an international, peer-reviewed, open access, online journal focusing on the latest clinical and experimental research in dentistry with specific emphasis on cosmetic interventions. Innovative developments in dental materials, techniques and devices that improve outcomes and patient satisfaction

\section{Dovepress}

and preference will be highlighted. The manuscript management system is completely online and includes a very quick and fair peerreview system, which is all easy to use. Visit http://www.dovepress. com/testimonials.php to read real quotes from published authors.

Submit your manuscript here: http://www.dovepress.com/clinical-cosmetic-and-investigational-dentistry-journal 